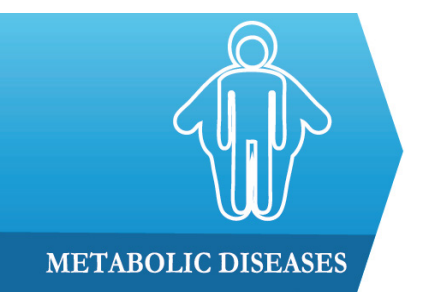

1) Department of Pharmacology, A. J. Institute of Medical Sciences and Research Centre, Mangaluru-575004, Karnataka, India

2) A. J. Research Centre, A. J. Institute of Medical Sciences and Research Centre, Mangaluru-575004, Karnataka, India

* Both authors have equal contributions to this study

\title{
Diabetogenic effect of gluten in Wistar albino rats: a preliminary preclinical screening
}

\author{
Robin Shetty ${ }^{1}$, Mohandas Rai ${ }^{1}$, Rajan Chandrashekar ${ }^{1 *}$, \\ Bhuvanesh Sukhlal Kalal ${ }^{2 *}$
}

\begin{abstract}
Background and aims. Gluten-related disease affects less than $1 \%$ population and is not considered of relevance at the public health level. However, the consumption of a gluten-free diet has been most commonly adopted as a special diet worldwide in the recent past. In the present study, we investigated the association of gluten intake and diabetes in Wistar albino rats.
\end{abstract}

Methods. Thirty adult Wistar rats were randomly divided into five groups: control, diabetic, and test treated with pure gluten (100, 200 and $400 \mathrm{mg} / \mathrm{kg}$ body weight). Diabetes was induced in rats by intraperitoneal injection of Streptozotocin $(65 \mathrm{mg} /$ $\mathrm{kg}$ ) after a dose of nicotinamide $(110 \mathrm{mg} / \mathrm{kg})$. Body weight, fasting blood glucose levels, postprandial blood glucose levels and histopathology of the pancreas were compared.

Results. Fasting blood glucose levels and postprandial blood glucose were significantly higher in diabetes animals but there were no significant changes in gluten treated groups. Other parameters were not significantly changed among different groups.

Conclusions. Gluten at doses $100 \mathrm{mg} / \mathrm{kg}, 200 \mathrm{mg} / \mathrm{kg}$ and $400 \mathrm{mg} / \mathrm{kg}$ is not a diabetogenic diet and hence it needs not be excluded from diet for the prevention and management of Type 2 diabetes mellitus.

Keywords: animals, blood glucose, diabetes mellitus, glutens, niacinamide, streptozocin

\section{Introduction}

Diabetes mellitus (DM) is a metabolic disorder of several etiologies characterized by prolonged hyperglycemia with disturbances of carbohydrates, fat and protein metabolism resulting from defects in insulin secretion, insulin action, or both [1]. It is a growing public health concern worldwide. The prevalence of diabetes is increasing fast becoming an epidemic in some countries of the world [2]. Type-2 diabetes mellitus (T2DM) is characterized by insulin insensitivity due to insulin resistance, diminishing insulin production and subsequent pancreatic $\beta$-cell failure. Lifestyle factors and genetics play a role in the development of T2DM [3]. Various aspects of diet causing insulin resistance have been hypothesized, over the long term, to influence the risk of T2DM. It has been observed in metabolic studies that carbohydrates with a high glycemic index (a qualitative indicator of carbohydrate's ability to raise blood glucose levels) seem to increase insulin demand and accentuate hyperinsulinemia [4]. Type-1 diabetes mellitus (T1DM) is an autoimmune disorder caused by the destruction of the insulin-producing $\beta$-cells of the pancreas followed by absolute insulin deficiency and hyperglycemia [5].

The taxonomic classification of cereals sub classifies wheat, rye, and barley under the gluten tribe. Prolamin which is further separated into gliadins 
and glutenins are the main proteins in Gluten. They differ from other storage proteins as they are present in larger amounts, have a higher molecular mass and are insoluble in water because of the hydrophobic repeated sequences [6]. The toxic effect of these prolamins includes the reduction of F-actin, inhibition of cellular growth, premature cell death, the change of the cytoskeleton and amplified small bowel permeability. Gluten is partly resistant to enzymatic processing in the intestine and thus varies from other cereal proteins [7]. Consumption of gluten is therefore likely to result in persistent high concentrations of nondegradable gluten peptides.

Over the past few years, the gluten-free diet has gained popularity worldwide because many believed that eating a gluten-free diet leads to health-related benefits. Walker-Smith at al. first reported the association between Coeliac disease (CD) and T1DM (8), which is a metabolic disorder which accounts for $5-10 \%$ of all diabetes cases. Several studies have revealed the correlation between the intake of gluten and the subsequent development of T1DM $[7,9,10]$. Studies have shown that gluten affects the pancreatic $\beta$-cells by directly acting on the ATPsensitive potassium channels. $\beta$-cell stress raises the antigen expression which can, in turn, lead to increased incidence of diabetes. A study was done by Jorgensen et al., demonstrated that gluten-free diet increases $\beta$-cell volume and improves glucose tolerance in B6 mice and established that long term gluten-free diet may be beneficial for T2DM patients [11].

However, not many studies have been done to demonstrate the causal relationship between gluten and T2DM. Hence the present study was conducted to examine the potential diabetogenic impact of gluten. We investigated the association of gluten intake on blood glucose levels and the possible damage to the $\beta$-cells in the pancreatic tissue in Wistar albino rats over a period of time.

\section{Materials and methods Chemicals}

Standard drug Streptozotocin and nicotinamide were purchased from Sigma Chemical Company. St. Louis, USA. Streptozotocin was dissolved in citrate buffer ( $\mathrm{pH} 4.5)$ and Nicotinamide in normal saline. Streptozotocin was dissolved in citrate buffer $(\mathrm{pH} 4.5)$, Nicotinamide in normal saline.

Pure wheat gluten was procured from the Vintop products Pvt. Ltd, Bangalore, India. Nutrition constituents of the procured gluten powder are as follows; total calories $(0)$, total fat $(0 \mathrm{~g})$, cholesterol $(0 \mathrm{mg})$, sodium $(0$ $\mathrm{mg})$, total carbohydrate $(0 \mathrm{~g})$, protein $(85 \mathrm{~g})$, vitamin A
$(0 \%)$, vitamin C $(0 \%)$, calcium $(0 \%)$ and iron $(0 \%)$. Since gluten was not clearly soluble in distilled water, $1 \%$ gum acacia was used to dissolve gluten.

\section{Animals}

Adult Wistar rats of either sex were obtained from the Central Animal House, A. J. Institute of Medical Sciences, Mangaluru, India bearing registration number 1075/PO/Re/S/07/CPCSEA. Prior to experiment ethical approval was obtained from the Institutional Animal Ethical Committee under the reference number IAEC/02/2016/CPCSEA.

Rats were housed in clean polypropylene cages, six rats in each cage, in a controlled environment ( $24 \pm$ $2^{\circ} \mathrm{C}$ ) with 12-hour light and dark cycle. They were fed with commercial pelleted chow and water ad libitum. All efforts were made to minimize the animal suffering and the number of animals used. Following experimentation, all the animals were rehabilitated at the Central Animal House facility. Committee for the Purpose of Control and Supervision of Experiments on Animals (CPCSEA) guidelines were followed throughout the experiment.

Induction of diabetes in experimental animals

Diabetes was induced by administering streptozotocin $(65 \mathrm{mg} / \mathrm{kg}$ body weight; i.p), following 15 min nicotinamide administration $(110 \mathrm{mg} / \mathrm{kg}$ body weight; i.p.) $[12,13]$. Random blood glucose was measured after $72 \mathrm{~h}$ of administration of streptozotocin-nicotinamide and animals blood glucose levels higher than $200 \mathrm{mg} / \mathrm{dL}$, referred to as diabetic animals, were included in group II as diabetic control and group III to V was given the gluten treatment $[14,15]$.

\section{Experimental design}

Animals were randomly divided into five groups (each group containing 6 rats) as follows:

Group I (Normal Control), animals with a normal diet, received $1 \%$ of gum acacia orally(equivalent volume of gluten) for 90 days.

Group II (Diabetic Control), streptozotocinnicotinamide induced diabetic animals with a normal diet, received $1 \%$ of gum acacia orally (equivalent volume of gluten) for 90 days.

Group III (Test G100), animals which received gluten dissolved in $1 \%$ gum acacia at doses of $100 \mathrm{mg} / \mathrm{kg}$ body weight for 90 days.

Group IV (Test G200), animals which received gluten dissolved in $1 \%$ gum acacia at doses of $200 \mathrm{mg} / \mathrm{kg}$ body weight for 90 days.

Group V (Test G400), animals which received gluten dissolved in $1 \%$ gum acacia at doses of $400 \mathrm{mg} / \mathrm{kg}$ body weight for 90 days.

Animal groups are illustrated in Figure 1. 


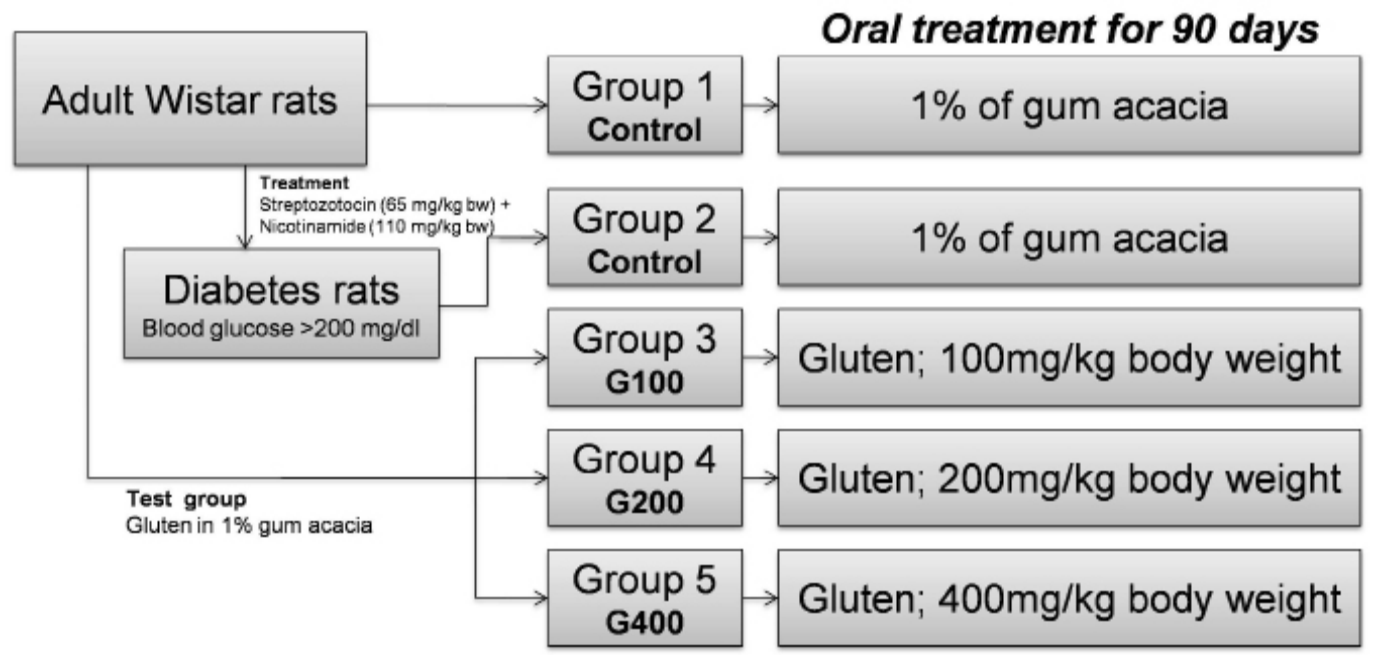

Figure 1. Animal groups and design of the experiment.

All the drugs were administered once daily orally. Body weights of rats were checked on the first day, then every week for the first one month and every month for another 3 months. The animals were also monitored for any behavioral changes during the study period.

\section{Blood collection and biochemical assessment}

Blood was collected from the tail vein of animals. Biochemical parameters like fasting blood glucose levels and postprandial blood glucose levels were checked on the first day, then every week for the first one month and every month for another 3 months.

Blood glucose levels were determined by a glucometer (Elegance CT-X10, convergent technologies, Germany) and biochemical assay kits (Pars Azmoon, Iran), with a sensitivity of $0.1 \mathrm{mg} / \mathrm{dl}$.

After the completion of the experiment, i.e. after 90 days, rats were sacrificed after giving euthanasia, dissection was performed and head of the pancreas was separated and was sent to a pathology laboratory for histopathological examination.

\section{Statistical analysis}

Mean values of all the parameters were calculated. The data are presented as mean \pm SD. The comparison between the diabetic group and the test groups was performed using one-way ANOVA. A p-value of less than 0.05 was considered significant. All data were analyzed statistically using GraphPad Prism 6 software (San Diego, CA, USA).

\section{Results}

Random blood glucose level was significantly increased in group II after two diabetic inductions when compared to Group I (Table I). However, there was no significant change in the mean fasting blood sugar levels in any of the test groups (group III, IV and V) compared to the normal control group on $8^{\text {th }}$ to $90^{\text {th }}$ day of the experiment. Similarly, mean postprandial blood sugar levels were significantly increased in diabetes animals but did not change in gluten treated test animals of group III, IV and V (Table II). On the $8^{\text {th }}$ day, random blood glucose level was increased but no significant while postprandial blood sugar levels found significant higher diabetes animals.

Table I. Fasting Blood Sugar (mg/dL) in control, diabetic and gluten treated rats.

\begin{tabular}{|c|c|c|c|c|c|c|c|}
\hline Group & $1^{\text {st }}$ Day & $8^{\text {th }}$ Day & $15^{\text {th }}$ Day & $21^{\text {st }}$ Day & $28^{\text {th }}$ Day & $60^{\text {th }}$ Day & $90^{\text {th }}$ Day \\
\hline 1. Normal Control & $80 \pm 3.26$ & $78.33 \pm 2.28$ & $80 \pm 3.14$ & $79.67 \pm 2.99$ & $79.57 \pm 3.53$ & $79.37 \pm 2.60$ & $84 \pm 1.71$ \\
\hline 2. Diabetic Control & $83 \pm 6.51$ & $142.17 \pm 47.02$ & $160.67 \pm 38.48 *$ & $204.33 \pm 73.31^{*}$ & $124.5 \pm 24.47^{*}$ & $279 \pm 66.61^{* *}$ & $337.17 \pm 69.48 * *$ \\
\hline 3. Gluten G100 & $88.67 \pm 2.47$ & $96.17 \pm 5.07$ & $84.5 \pm 4.96$ & $70.83 \pm 3.02$ & $78.57 \pm 3.35$ & $66.57 \pm 4.49$ & $65.33 \pm 3.47$ \\
\hline 4. Gluten G200 & $91 \pm 5.62$ & $99.5 \pm 2.58$ & $82.83 \pm 3.95$ & $70.33 \pm 2.19$ & $78.33 \pm 4.48$ & $82.5 \pm 3.73$ & $68.5 \pm 1.59$ \\
\hline 5. Gluten G400 & $97.5 \pm 9.99$ & $103.67 \pm 3.46$ & $81.83 \pm 2.27$ & $80 \pm 2.10$ & $79.5 \pm 2.85$ & $79.17 \pm 2.46$ & $73.5 \pm 2.55$ \\
\hline
\end{tabular}

Observations are Mean \pm SEM, ANOVA followed Dunnett's multiple comparison test, p value $<0.05 *$, p value $<0.01 * *$ 
Table II. Postprandial blood sugar levels (Mean \pm SEM) in control, diabetic and gluten treated rats.

\begin{tabular}{|c|c|c|c|c|c|c|c|}
\hline Group & $1^{\text {st }}$ Day & $8^{\text {th }}$ Day & $15^{\text {th }}$ Day & $21^{\text {st }}$ Day & $28^{\text {th }}$ Day & $60^{\text {th }}$ Day & $90^{\text {th }}$ Day \\
\hline 1. Normal Control & $98 \pm 1.37$ & $100.67 \pm 1.76$ & $106.67 \pm 2.72$ & $107.33 \pm 2.81$ & $107.33 \pm 1.76$ & $109.57 \pm 0.95$ & $111.33 \pm 2.04$ \\
\hline 2. Diabetic Control & $94.33 \pm 5.64$ & $436.5 \pm 85.88 * *$ & $359 \pm 89.01 * *$ & $403.17 \pm 92.06^{* *}$ & $386.83 \pm 86.86^{* *}$ & $423.57 \pm 94.35^{* *}$ & $424.33 \pm 101.90 * *$ \\
\hline 3. Gluten G100 & $134 \pm 7.61$ & $135.33 \pm 11.26$ & $123.5 \pm 8.87$ & $129.5 \pm 11.64$ & $104.17 \pm 3.63$ & $114.83 \pm 6.80$ & $109 \pm 3.53$ \\
\hline 4. Gluten G200 & $131.33 \pm 17.56$ & $113.33 \pm 9.02$ & $108.5 \pm 3.70$ & $116.33 \pm 12.53$ & $103.17 \pm 1.54$ & $103.83 \pm 4.11$ & $107 \pm 5.43$ \\
\hline 5. Gluten G400 & $122.83 \pm 11.07$ & $117.83 \pm 5.99$ & $119.83 \pm 6.24$ & $110.17 \pm 6.31$ & $103.5 \pm 3.23$ & $115.17 \pm 5.88$ & $105.17 \pm 2.15$ \\
\hline
\end{tabular}

Observations are Mean \pm SEM, ANOVA followed Dunnett's multiple comparison test, p-value $<0.05 *$, p-value $<0.01 * *$. Only in standard groups, changes in postprandial sugar levels were very significant.

Table III. Body weight (Mean \pm SEM) of control, diabetic and gluten treated rats.

\begin{tabular}{|c|c|c|c|c|c|c|c|}
\hline Group & $1^{\text {st }}$ Day & $8^{\text {th }}$ Day & $15^{\text {th }}$ Day & $21^{\text {st }}$ Day & $28^{\text {th }}$ Day & $60^{\text {th }}$ Day & $90^{\text {th }}$ Day \\
\hline 1. Normal Control & $217.67 \pm 9.91$ & $219.37 \pm 8.12$ & $220 \pm 9.03$ & $219 \pm 9.25$ & $218.67 \pm 8.50$ & $219.67 \pm 7.65$ & $220 \pm 7.57$ \\
\hline 2. Diabetic Control & $210.57 \pm 12.75$ & $205 \pm 14.32$ & $205.83 \pm 16.48$ & $198.33 \pm 15.39$ & $197.17 \pm 15.64$ & $190.17 \pm 16.06$ & $172.5 \pm 16.96$ \\
\hline 3. Gluten G100 & $243.5 \pm 30.53$ & $245.67 \pm 29.76$ & $252.33 \pm 31.81$ & $246.16 \pm 29.20$ & $264.63 \pm 30.40$ & $250.5 \pm 30.33$ & $247.5 \pm 31.20$ \\
\hline 4. Gluten G200 & $251.16 \pm 33.23$ & $258 \pm 34.80$ & $249.17 \pm 32.98$ & $241.5 \pm 31.17$ & $263.17 \pm 34.16$ & $256.33 \pm 36.33$ & $253.33 \pm 32.11$ \\
\hline 5. Gluten G400 & $240.5 \pm 19.47$ & $260.5 \pm 19.83$ & $249.83 \pm 20.67$ & $248.33 \pm 20.51$ & $269.83 \pm 21.64$ & $248.33 \pm 20.54$ & $250.57 \pm 20.98$ \\
\hline
\end{tabular}

Observations are Mean \pm SEM, ANOVA followed Dunnett's multiple comparison test, $\mathrm{p}$ value $<0.05 *$, p value $<0.01 * *$

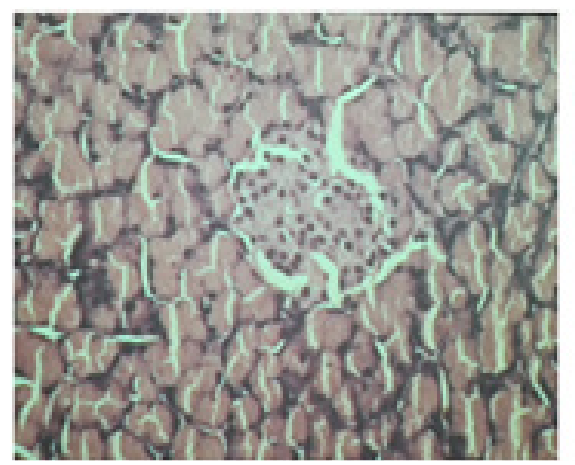

A

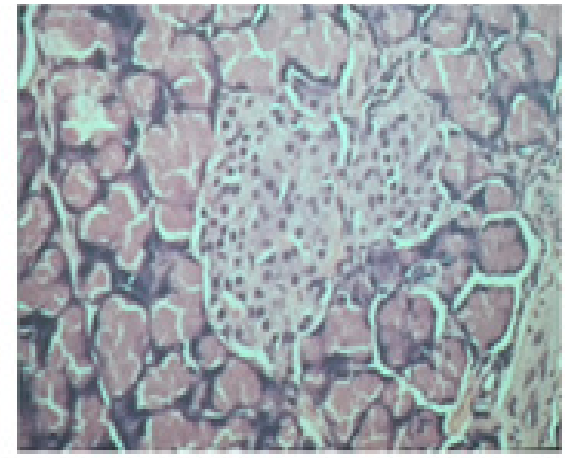

B

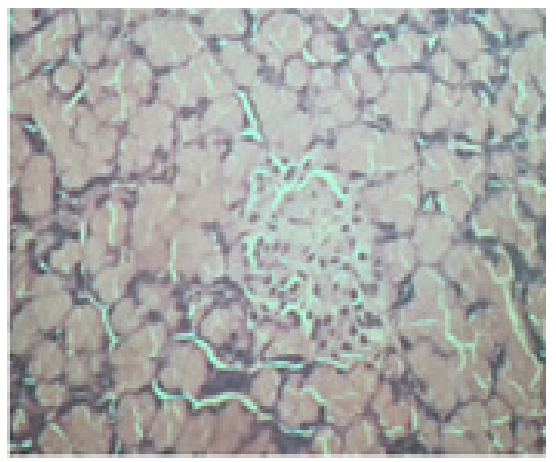

C

Figure 2. Histological picture of the head of pancreas gluten treated Wistar Rats. Gluten dose was: A - $100 \mathrm{mg} / \mathrm{kg}$ body weight; B - $200 \mathrm{mg} / \mathrm{kg}$ body weight, and $\mathbf{C}-400 \mathrm{mg} / \mathrm{kg}$ body weight.

There was no significant change in body weight between Group I and Group II on from the first week to three-month comparison. Gluten treated test group (group III, IV and V) showed a slight increase in body weight but it was not statistically significant when compared to Group I and II (Table III).

Histopathological report of test groups revealed that there was no increase in the number and size of the islets, no necrosis of the $\beta$-cells, and no inflammatory lesions in the exocrine parenchyma and there was no degranulation of the $\beta$-cells. These reports suggested that there were no diabetic changes in the $\beta$-cells of the head of the pancreas in test groups with gluten at doses 100 $\mathrm{mg} / \mathrm{kg}, 200 \mathrm{mg} / \mathrm{kg}$ and $400 \mathrm{mg} / \mathrm{kg}$ body weight (Figure 2).

\section{Discussion}

Diabetes mellitus is one of the chronic disorders which accounts for about $10 \%$ of the diseases in the world's population [16]. Among different types of diabetes, T2DM is the commonest one. To start with, it presents as an increase in the glucose levels of blood and in the long term it can result in severe impairment and failure of various organs [17,18]. By controlling T2DM effectively, we can prevent long term complications associated with the disease.

The various risk factors like genetic, environmental, and metabolic are interrelated and contribute to the progression of T2DM [19]. A major goal in the management includes lifestyle management which comprises of diet control, physical activity and oral hypoglycemic 
medications. The diet and diabetes association has received a great deal of scientific attention and effort to evaluate dietary intake precisely. Dietary interventions play a key role in the prevention of T2DM [20].

Gluten is referred as a complex protein which is found in certain grains like wheat, rye, and barley. Gluten altered the intestinal microbiota that maintains the intestinal permeability [16]. These bacteria produce shortchain fatty acids by the breakdown of dietary fibers which includes butyrate, acetate, and propionate. Butyrate and acetate induce intestinal permeability through lipoxygenase activation via histone acetylation [21]. Butyrate can also boost the number and functions of regulatory $\mathrm{T}$ cells which are known to suppress inflammatory responses [22]. Therefore, increased permeability leads to the production of a number of cytokines that can, in turn, promote inflammation and damage in the small intestine. Many studies have demonstrated the correlation between the intake of gluten and the subsequent development of T2DM $[4,7,10]$. Gluten is established to cause the destruction of $\beta$-cells in T1DM which is autoimmune in nature [9]. However, the scientific evidence associating gluten with T2DM is still lacking.

In the present study, pure gluten was used to determine its effect on blood glucose levels in adult WISTAR Albino strain rats over a period of time and to determine the possible damage to the $\beta$-cells of pancreatic tissue. Streptozotocin-Nicotinamide induced T2DM is a model that shares characteristic features with human T2DM. When nicotinamide was administered along with the streptozocin, it gives partial protection to insulinsecreting cells against streptozotocin, hence mimicking a T2DM like state [23].

The present study was conducted to evaluate the possible diabetogenic activity of gluten at doses 100 $\mathrm{mg} / \mathrm{kg}, 200 \mathrm{mg} / \mathrm{kg}$ and $400 \mathrm{mg} / \mathrm{kg}$ in rats. The results suggest that administration of gluten at doses $100 \mathrm{mg} /$ $\mathrm{kg}, 200 \mathrm{mg} / \mathrm{kg}$ and $400 \mathrm{mg} / \mathrm{kg}$ body weight for 90 days did not show any significant increase in the blood glucose levels and body weight in rats. Similarly, recently Zong et al., also showed an inverse association between gluten intake and T2DM risk among large cohort healthy US population [24].

Whereas streptozocin, a standard drug which was given along with the nicotinamide, significantly increased the blood glucose levels in rats. The results suggest that administration of gluten at doses $100 \mathrm{mg} / \mathrm{kg}, 200 \mathrm{mg} / \mathrm{kg}$ and $400 \mathrm{mg} / \mathrm{kg}$ body weight for 90 days did not show any significant increase in the blood glucose levels and body weight in rats.

Histopathological report of test groups revealed that there was no increase in the number and size of the islets, no necrosis of the $\beta$-cells, and no inflammatory lesions in the exocrine parenchyma and there was no degranulation of the $\beta$-cells. These reports suggested that there were no diabetic changes in the $\beta$-cells of the head of the pancreas in test groups with gluten at doses $100 \mathrm{mg} / \mathrm{kg}, 200 \mathrm{mg} /$ $\mathrm{kg}$ and $400 \mathrm{mg} / \mathrm{kg}$ body weight. Gluten intakes have no significant adverse effects on the incidence of T2DM or weight gain [25].

Still, there is a debate over the belief that simply avoiding or eliminating highly processed foods (including highly processed gluten-containing foods) may or may not have health benefits [26]. Limiting gluten intake may limit the beneficial nutrients like cereal fibers, micronutrients and minerals in the diet [27]. Therefore, careful investigation on how factors associated with this diet affect a variety of symptoms, including gastrointestinal function, cognition, and overall well-being is required.

\section{Conclusions}

Our preliminary results have shown that gluten has no effect on increasing the blood sugar level and body weight at doses $100 \mathrm{mg} / \mathrm{kg}, 200 \mathrm{mg} / \mathrm{kg}$ and $400 \mathrm{mg} / \mathrm{kg}$ in the experimental rats which were used in this study. The histopathological study which was done after the study also did not show any changes in the $\beta$-cells of the islets of the pancreas. The study infers that gluten may not a diabetogenic diet, but further studies required to see longterm effect of gluten consumption.

\section{Acknowledgments}

The authors would like to thanks A. J. Institute of Medical Sciences and Research Centre for providing facilities and funding for this project.

\section{References}

1. Diabetes Canada Clinical Practice Guidelines Expert Committee, Punthakee Z, Goldenberg R, Katz P. Definition, Classification and Diagnosis of Diabetes, Prediabetes and Metabolic Syndrome. Can J Diabetes. 2018;42 Suppl 1:S10-S15.

2. Animaw W, Seyoum Y. Increasing prevalence of diabetes mellitus in a developing country and its related factors. PLoS One. 2017;12:e0187670.

3. Leibowitz $G$, Kaiser N, Cerasi E. $\beta$-Cell failure in type 2 diabetes. J Diabetes Investig. 2011;2:82-91.

4. Sacks FM, Carey VJ, Anderson CA, Miller ER 3rd, Copeland $\mathrm{T}$, Charleston J, et al. Effects of high vs low glycemic index of dietary carbohydrate on cardiovascular disease risk factors and insulin sensitivity: the OmniCarb randomized clinical trial. JAMA. 2014;312:2531-2541.

5. Devendra D, Liu E, Eisenbarth GS. Type 1 diabetes: recent developments. BMJ. 2004;328:750-754.

6. Schalk K, Lexhaller B, Koehler P, Scherf KA. Isolation and characterization of gluten protein types from wheat, rye, barley and oats for use as reference materials. PLoS One. 2017; 12:e0172819. 
7. Antvorskov JC, Josefsen K, Engkilde K, Funda DP, Buschard K. Dietary gluten and the development of type 1 diabetes. Diabetologia. 2014;57:1770-1780.

8. Walker-Smith JA, Vines R, Grigor W. Coeliac disease and diabetes. Lancet. 1969;2:650.

9. Larsen J, Weile C, Antvorskov JC, Engkilde K, Nielsen SM, Josefsen $\mathrm{K}$, et al. Effect of dietary gluten on dendritic cells and innate immune subsets in BALB/c and NOD mice. PLoS One. 2015;10:e0118618.

10. Antvorskov JC, Halldorsson TI, Josefsen K, Svensson J, Granström C, Roep BO, et al. Association between maternal gluten intake and type 1 diabetes in offspring: national prospective cohort study in Denmark. BMJ. 2018;362:k3547. Epub 2018/09/21.

11. Haupt-Jorgensen M, Buschard K, Hansen AK, Josefsen K, Antvorskov JC. Gluten-free diet increases beta-cell volume and improves glucose tolerance in an animal model of type 2 diabetes. Diabetes Metab Res Rev. 2016;32:675-684.

12. Madkor HR, Mansour SW, Ramadan G. Modulatory effects of garlic, ginger, turmeric and their mixture on hyperglycaemia, dyslipidaemia and oxidative stress in streptozotocinnicotinamide diabetic rats. Br J Nutr. 2011;105:1210-1217.

13. Mojani MS, Sarmadi VH, Vellasamy S, Sandrasaigaran P, Rahmat A, Peng LS, et al. Evaluation of metabolic and immunological changes in streptozotocin-nicotinamide induced diabetic rats. Cell Immunol. 2014;289:145-149.

14. Catassi C, Rossini M, Rätsch IM, Bearzi I, Santinelli A, Castagnani $\mathrm{R}$, et al. Dose dependent effects of protracted ingestion of small amounts of gliadin in coeliac disease children: a clinical and jejunal morphometric study. Gut. 1993;34:1515-1519.

15. Cheng CC, Etoh J, Tanimura T, Egashira Y, Ohta T, Sanada H. Effects of dietary gluten on the hepatotoxic action of galactosamine and/or endotoxin in rats. Biosci Biotechnol Biochem. 1996;60:439-443.

16. Murri M, Leiva I, Gomez-Zumaquero JM, Tinahones FJ, Cardona F, Soriguer F, et al. Gut microbiota in children with type 1 diabetes differs from that in healthy children: a casecontrol study. BMC Med. 2013;11:46.
17. Long AN, Dagogo-Jack S. Comorbidities of diabetes and hypertension: mechanisms and approach to target organ protection. J Clin Hypertens (Greenwich). 2011;13:244-251.

18. Petrie JR, Guzik TJ, Touyz RM. Diabetes, Hypertension, and Cardiovascular Disease: Clinical Insights and Vascular Mechanisms. Can J Cardiol. 2018;34:575-584.

19. Gosadi IM. Assessment of the environmental and genetic factors influencing prevalence of metabolic syndrome in Saudi Arabia. Saudi Med J. 2016;37:12-20.

20. Guess ND. Dietary Interventions for the Prevention of Type 2 Diabetes in High-Risk Groups: Current State of Evidence and Future Research Needs. Nutrients. 2018;10. doi: 10.3390/nu10091245.

21. Ohata A, Usami M, Miyoshi M. Short-chain fatty acids alter tight junction permeability in intestinal monolayer cells via lipoxygenase activation. Nutrition. 2005;21:838-847.

22. Mariño E, Richards JL, McLeod KH, Stanley D, Yap YA, Knight J, et al. Gut microbial metabolites limit the frequency of autoimmune $\mathrm{T}$ cells and protect against type 1 diabetes. Nat Immunol. 2017;18:552-562.

23. Szkudelski T. Streptozotocin-nicotinamide-induced diabetes in the rat. Characteristics of the experimental model. Exp Biol Med (Maywood). 2012;237:481-490.

24. Zong G, Lebwohl B, Hu FB, Sampson L, Dougherty LW, Willett WC, et al. Gluten intake and risk of type 2 diabetes in three large prospective cohort studies of US men and women. Diabetologia. 2018;61:2164-2173.

25. Kim HS, Patel KG, Orosz E, Kothari N, Demyen MF, Pyrsopoulos N, et al. Time Trends in the Prevalence of Celiac Disease and Gluten-Free Diet in the US Population: Results From the National Health and Nutrition Examination Surveys 2009-2014. JAMA Intern Med. 2016;176:1716-1717.

26. Miller D. Maybe It's Not the Gluten. JAMA Intern Med. 2016;176:1717-1718.

27. Lerner BA, Green PHR, Lebwohl B. Going Against the Grains: Gluten-Free Diets in Patients Without Celiac DiseaseWorthwhile or Not? Dig Dis Sci. 2019;64:1740-1747. 